\title{
Políticas habitacionais brasileiras: a elucidação de um padrão de segregação socioeconômica e socioespacial
}

Brazilian housing politics: elucidating a pattern of socioeconomic and socio-spatial segregation

\section{Gabriella Rosa Maciel Gomes \\ gabriellagomes@live.com}

Aluna de graduação em Geografia e Meio

Ambiente - PUC-Rio

\begin{abstract}
Resumo
Este artigo apresentará uma análise sobre as políticas habitacionais brasileiras com o objetivo de expor as ineficiências do poder público em desenvolver infraestrutura, uso igualitário do território para todos e o êxito em instaurar um padrão de segregação visível. Palavras-chave: direitos humanos; cidade; políticas habitacionais; segregação espacial; segregação socioeconômica.
\end{abstract}

\footnotetext{
Abstract

This paper aims to present an analysis of Brazilian housing politics, exposing the inefficiency of the public power in developing infrastructure, equitable use of territory and the establishment of a visible segregation pattern.

Keywords: human rights; city; housing politics; spatial segregation; socioeconomic segregation.
} 


\section{Introdução}

A cidade é produto, condição e meio de reprodução dos conflitos e interesses do público x privado. O molde das nossas cidades está atrelado historicamente aos interesses da hegemônica classe dominante brasileira de caráter intocável, cujo principal alicerce é a exploração da pobreza em detrimento do desamparo do Estado. A população que sofre com a precarização e falta de acesso a moradia é a mais vulnerável, ou seja, a classe pobre da nossa sociedade, e mesmo sendo prejudicada secularmente, inconscientemente sustenta toda essa organização.

Mesmo quando é identificada a necessidade de desenvolvimento da questão social, só há efetivo desenvolvimento quando a questão econômica é preponderante ou, em casos extremos, quando danos e prejuízos acarretam o comprometimento substancial do poder público. Assim, o Estado nega a dignidade humana e o bem-estar social da população pobre em diversos momentos históricos, principalmente quando o destino dessas famílias de baixa renda é subjugado e subordinado por projetos que não são compatíveis com a realidade de muitos. O fato é que os grupos sociais que conduzem as políticas de modernização espacial pouco se importam com as alterações feitas, tão pouco pensam como tais mudanças podem vir a afetar negativamente àqueles que não têm acesso aos processos decisórios. Em virtude da omissão e da passividade do Estado diante do desafio de lidar com a complexificação múltipla da sociedade brasileira, cidades não transpõem características homogêneas e estão longe de alcançar um uso igualitário.

O problema da moradia está intrinsecamente relacionado à negação do direito à cidade aos mais pobres, isso reflete os ciclos de políticas que não elucidam a real demanda habitacional dos cidadãos desfavorecidos ou, em alguns períodos, simplesmente inexistiam. Mediante o exposto, torna-se indispensável contextualizar como o Estado enfrenta a questão da habitação urbana no Brasil através de projetos e políticas.

\section{Linha temporal das políticas habitacionais no Brasil}

No final do século XIX, estratégias políticas e acontecimentos ressignificaram o uso e o valor da terra no Brasil, que deixa de ser exponencial à vida, como afirma o jurista Marés “a terra sempre foi, para todos os povos, a fonte da vida, seja para colher os alimentos seja para produzir cada objeto" (SOUZA FILHO, 2015, p.58) e passa a ser utilizada principalmente como 
mercadoria de compra. No território brasileiro, essa relação muda substancialmente a partir da famigerada Lei de Terras de $1850^{1}$, que atribuiu valor monetário à terra, ou seja, atribuiu valor de compra e venda, extirpando a dinâmica secular de aquisição por meio da posse.

A mudança do meio de aquisição de terra culminou também na mudança da relação de uso e da relação social da época. Impôs barreiras aos de negros que foram sequestrados da África e submetidos ao trabalho escravo e aos imigrantes europeus pobres que chegaram no Brasil com o intuito de produzir a subsistência e viver da terra. Foi uma estratégia jurídica para definir quem poderia ser proprietário de terra e quem não poderia, conforme afirma Emília Maricato:

\begin{abstract}
A definição e demarcação das terras devolutas, após 1850, foi uma das maiores farsas que marcaram a história do Brasil. Ela se assemelha a farsa que marcou a proibição do tráfico de escravos entre 1831 e 1850 - isso é, era proibido, mas feito à luz do dia e envolvendo autoridades de prestígio na sociedade brasileira. (2000, p.148)
\end{abstract}

Melhor dizendo, a lei de terras foi um mecanismo para dificultar o acesso aos trabalhadores supracitados e manter a concentração da propriedade privada da terra nas mesmas mãos. Outros marcos temporais importantes estão relacionados à ascensão da produção cafeeira em $1860^{2}$ devido ao quadro internacional favorável, à Lei Áurea de $1888^{3}$, acompanhadas pela migração em massa nunca vista antes no país, que trouxe desafios do mesmo viés. Pois o aumento de pessoas nas cidades ocasionou maior demanda por moradia, emprego, transporte, serviços essenciais para o desenvolvimento, o que conduz o Brasil a uma embrionária industrialização e urbanização.

No início do século XX, o poder do Estado era controlado pela elite oligárquica concentrada principalmente pela aristocracia rural (grandes proprietários de terras), ou seja, um Estado que visava concentrar renda e expandir os privilégios sobre a classe dominada, atuando de maneira a consolidar o poder político e econômico dos seus afins. Como salienta Perissinotto $^{4}$, o "regime político excludente (oligárquico), é calcado nas relações de dependência pessoal predominantes no campo brasileiro, no coronelismo e na política dos governadores, sobre a forma de Estado democrática" (1996, p.193). O aparelho do Estado

\footnotetext{
1 Lei número 601 de 18 de setembro de 1850, foi uma das primeiras leis brasileiras após a independência de 1822.

${ }^{2}$ Para entender melhor o momento histórico, ler: SILVA, Sergio. Expansão cafeeira e origens da indústria no Brasil. São Paulo: Alfa-Omega, 1976.

${ }^{3}$ Chamada de Lei Imperial n 3.353, que determinou oficialmente a abolição da escravatura no Brasil.

${ }^{4}$ Renato Monseff Perissinotto, professor titular da Universidade Federal do Paraná.
} 
exigia reorganização das condições econômicas, sociais e políticas, pois os moldes que inibiam o bem-estar social e o desenvolvimento da sociedade já estavam ultrapassados, a população apresentava insatisfação às contradições sociais da época. Prova disso é a organização da sociedade civil para o meio de sindicatos e movimentos sociais populares criados a partir do início do século.

A tarefa de produzir habitações sociais para as classes desfavorecidas foi incumbida a instituições privadas, através de créditos às empresas, todavia, para os empresários do ramo não era interessante a construção de vilas operárias e cortiços, devido à baixa rentabilidade. Só houve considerais mudanças urbanísticas no Brasil no início do século XX, sendo esta tardia, lenta e desigual. Isso caracterizou resultados similares ao período colonial e imperial, a partir da concentração de terra, renda e poder, que reproduzia o coronelismo e a aplicação arbitrária de leis. Harvey afirma que em uma sociedade capitalista, a urbanização é um meio fundamental para absorver o capital excedente, pois implica superioridade de uma classe sobre a outra, estabelecendo dificuldades de acesso, relações sociais desiguais, segregação territorial, com o plano de fundo: manutenção de poder concentrado; privilégios à elite. Salienta Harvey:

\begin{abstract}
A reprodução do capital passa por processos de urbanização de inúmeras maneiras. Contudo, a urbanização do capital pressupõe a capacidade de o poder de classes capitalistas dominar o processo urbano. Isso implica na dominação da classe capitalista não apenas sobre os aparelhos do Estado (...) como também sobre populações inteiras. (2012 p.133)
\end{abstract}

Diversas cidades brasileiras passaram por problemas relativos à falta de planejamento habitacional, devido à ineficiência e inexperiência do poder público, medidas incapazes de atender às demandas e à necessidade de uma sociedade diversificada. No início do século XX, o Rio de Janeiro passou por diversos processos de reformas urbanas para melhorar a circulação de mercadorias, serviços e pessoas na cidade. A operação "Bota-Abaixo"5 chamou a atenção devido à maneira radical pela qual foi implementado o conjunto de obras. Nessa ocasião, foram demolidas diversas construções antigas que eram relacionadas com as precárias condições sanitárias, em especial as coletivas, o que acarretou a expulsão de diversas famílias pobres de suas moradias humildes. Elas foram obrigadas a migrar para os subúrbios gerando a formação

\footnotetext{
${ }^{5}$ Expressão criada para designar, ao mesmo tempo, o processo de reformas urbanas operado a partir de 1903 no Rio de Janeiro, então Distrito Federal, e o prefeito da cidade à época, Francisco Pereira Passos (1902-1906). Com a expressão o "Bota-Abaixo", buscou-se destacar a maneira radical pela qual foi implementado um conjunto de obras públicas que então redefiniram a estrutura urbana da capital federal. Disponível em: https://atlas.fgv.br/verbetes/o-bota-abaixo Acesso em: 12 set 2019.
} 
das primeiras favelas periféricas do estado do Rio de Janeiro, seguindo um modelo adaptado do planejamento de cidades europeias, em especial Paris, conciliando o embelezamento com o saneamento e, contraditoriamente, a circulação com a segregação territorial.

O homem empobrecido no Rio de Janeiro sempre foi segregado do direito de morar em determinados espaços da cidade, especialmente naqueles ditos nobres. No final do século XIX e início do século XX, houve o desmonte dos cortiços que ao tentar afastar os empobrecidos dos espaços nobres acabou potencializando a expansão de um novo tipo de agrupamento habitacional que vinha surgindo - as favelas. (SOUSA, 2003, p.48)

Entretanto, as políticas para habitação só começaram a se desenvolver na década de 1930, com a regularização do trabalho urbano, impulsionando industrialização, urbanização, corroborando a migração campo-cidade, conduzida pela Revolução de $30^{6}$. Vale salientar que todas as medidas aderidas pós Revolução de 30 não foram frutos de planos de governo preestabelecidos e sim respostas às demandas sociais, econômicas, políticas e militares em que as demandas urbanas e sociais ganharam maior relevância, pois a maioria das cidades brasileira estavam associadas à imagem do caos.

O setor privado não foi capaz de suprir as necessidades habitacionais como tampouco havia sido no passado. Esses problemas referentes à habitação deveriam ser executados pelo poder público, pois a sociedade brasileira demandava infraestrutura, inserção econômica e melhoria de vida, exigências mínimas para a existência plena que eram caras ao Estado.

Como resposta à escassez de moradia, o Estado, principal financiador através dos incentivos à iniciativa privada das habitações populares, em 1937 passa a resolver os problemas relativos a favelas e aos favelados com meditas que não abrangiam a sua totalidade. Em um segundo momento, com a adoção de política de erradicação de favelas, de uma maneira geral projetos e políticas aplicadas com viés integracionista eram ineficientes e insuficientes, pois, as medidas não contemplavam quem mais precisava - os mais pobres -, e dessa forma só acentuava mais a desigualdade.

A crise da habitação colocou a questão em pauta pública, no período populista ${ }^{7}$. Em 1946, foi criada a Fundação da Casa Popular $(\mathrm{FCP})^{8}$, que representou o primeiro esforço declarado

\footnotetext{
${ }^{6}$ Também conhecido como Golpe de 30, que derrubou o então presidente da república Washington Luís em 24 de outubro de 1930, impediu a posse do presidente eleito Júlio Prestes e deu fim à República Velha. Getúlio Vargas assim assume a Chefia do Governo Provisório.

${ }^{7}$ Refiro-me ao governo do presidente Getúlio Vargas de 1930 a 1945.

8 Fundação da Casa Popular (FCP), primeiro órgão federal destinado especificamente à produção habitacional no Brasil, instituída em 1946 e extinta com a criação do BNH (Banco Nacional de Habitação) em 1964.
} 
do Estado no trato com o problema das moradias, visando atender a população que não participava do mercado formal de trabalho. Os trabalhadores do mercado formal tinham acesso aos benefícios do antigo Instituto de Aposentadoria e Pensões (IAPs) ${ }^{9}$ que, entre outras coisas, fizeram grandes investimentos em habitação para os seus beneficiários.

Assim, ficou patente a extensão das atividades da FCP, de financiar desde casas tipo popular até indústrias de matérias de construção, passando por serviços de urbanização, criando uma relação de financiamento e acessória. As intenções pareciam bem fundamentadas ao pretender o atendimento dos numerosos indivíduos não cobertos pelas categorias de operários das IAPs e tentar financiar habitações para pessoas com rendimentos mínimos, um projeto muito maior e ainda mais dedicado financeiramente do que a que prestou inicialmente com as IAPs.

Porém, devido à postura autoritária e às relações clientelistas de natureza do período populista, somadas ao acúmulo de atribuições, a mal dimensionada concepção, a falta de recursos e de forças políticas, o projeto culminou no fracasso e sua extinção em 1964, no golpe militar. O primeiro plano do governo militar foi a criação o Plano Nacional de Habitação (PNH), cuja execução seria financiada pelo Banco Nacional de Habitação $(\mathrm{BNH})^{10}$, órgão federal que compunha o Sistema Financeiro de Habitação (SFH). A captação de recursos era realizada através do recém-criado Fundo de Garantia por Tempo de Serviço (FGTS) e de letras imobiliárias, que buscavam dinamizar a economia, desenvolver o país gerando empregos, e fortalecer o setor da construção civil, mas, sobretudo, controlar as massas, visando solucionar o caos urbano, controlando o crescimento das favelas e ocupações irregulares.

O sistema efetivado no regime militar facilitou a implementação de projetos de infraestrutura urbana, que alcançou substancial desenvolvimento no planejamento com a introdução dos planos diretores, em números nunca vistos no país. Todavia, ignorando as problemáticas e necessidades reais da cidade, a política de habitação do período não concentrou esforços na produção de infraestrutura e moradias para os cidadãos das cidades informais (vilas

9 O objetivo principal dos IAPs era reorganizar o setor previdenciário. Isso incluía garantir aposentadorias e pensões aos seus associados, assisti-los no caso de adoecimento, incapacidade ou morte do chefe de família, IAPs fizeram grandes investimentos em habitação, para maiores informações ler: A produção da habitação e os conjuntos habitacionais dos institutos de aposentadorias e pensões - IAPs, por Cristina Maria Perissinotto Baron.

10 Pela Lei no 4.380, de 21 de agosto de 1964, foi instituído o Plano Nacional da Habitação e criado o Banco Nacional da Habitação, com sede no Rio de Janeiro. O banco deveria ser o gestor e financiador de uma política destinada a "promover a construção e aquisição da casa própria, especialmente pelas classes de menor renda". 
e favelas) e mais uma vez o real "problema" foi negligenciado. Os planos eram elaborados por especialista com escasso engajamento da realidade social e cultural, segundo Azevedo:

Apesar de todos os esforços realizados, o BNH não conseguiu atingir satisfatoriamente os setores de renda mais baixa através dos programas tradicionais. Ressalte-se que o Banco tinha como clientela prioritária as famílias de renda mensal entre um e três salários mínimos. (1988 p.112)

A única alternativa viável para as famílias pobres eram as favelas e loteamento ilegais irregulares periféricos e centrais, "sem poder pagar pelo seu preço nas áreas mais equipadas, deslocaram-se para mais longe, ampliando o processo de periferização" ( SANTOS, p.124, 1993). Devido aos baixos custos, à autoconstrução e à pouca fiscalização, a situação culmina no aumento crescente de números de favelas. As políticas de habitação não tiveram grande efetividade e não cumpriram as metas existentes, pois ignoraram o fato de que a pobreza é resultante de sociedades que negligenciam os direitos de alguns em detrimento do direito de outros. Em 1980, a instabilidade financeira impactou diretamente o SFH, resultando na extinção do BNH anos depois, que transfere suas funções para a Caixa Econômica Federal (CAIXA). Isso tornou mais difícil o acesso dos pobres à moradia digna, pois a Caixa é uma instituição bancária e necessitava se capitalizar para dinamizar seus rendimentos, como afirma Azevedo:

\begin{abstract}
A incorporação das atividades do BNH à Caixa Econômica Federal fez com que a questão urbana e especialmente a habitacional passasse a depender de uma instituição em que estes temas, embora importantes, são objetivos setoriais. Do mesmo modo, ainda que considerada como agência financeira de vocação social, a Caixa possui, como é natural, alguns paradigmas institucionais de um banco comercial, como a busca de equilíbrio financeiro, retomo do capital aplicado etc. (1988, p.118)
\end{abstract}

Com a Constituição Brasileira de 1988, houve a descentralização das políticas públicas de habitação e o planejamento urbano, ficando a cargo de cada município o desenvolvimento das políticas habitacionais devido às diferentes demandas. De certo modo, foi uma medida que visava ampliar a eficiência, eficácia e a efetividade local, entretanto, prejudicava municípios mais pobres pela limitação dos recursos. Assim, os avanços passam a estar assegurados no papel, porém não transpassam o papel. 
Fernando Collor ${ }^{11}$, em seu governo, lançou o Plano de Ação Imediata para Habitação (PAIH). Como o nome já explica, foi um projeto que visava medidas imediatas em curto prazo, que o governo não cumpriu. Itamar Franco ${ }^{12}$, ao assumir, por sua vez, criou os projetos Programa Habitar Brasil e Morar Municipal, mas devido à burocracia muitos municípios não eram contemplados com os recursos. Contudo, houve dois consideráveis avanços: a formação de conselhos e a criação de fundos para habitação; o Fórum Nacional de Habitação era composto de representantes da sociedade civil, Estado e empresários, uma coalizão valiosa para atender os interesses da sociedade, do público e do privado.

O governo de Fernando Henrique Cardoso $(\mathrm{FHC})^{13}$ partiu de um diagnóstico do problema habitacional do Brasil e, a partir disso, instituiu: o reconhecimento da cidade legal e a extensão dos direitos e da cidadania; o conceito de déficit que incorporou áreas ocupadas precariamente (favelas); e a descentralização de programas, tais como: Pró-moradia; Habitar Brasil; Carta de Crédito Individual Associativa; Apoio à Produção.

No entanto, o marco importante no governo FHC foi a aprovação, pelo Congresso Nacional e promulgação presidencial, do Estatuto da Cidade, em 2001, depois de 13 anos de tramitação. O Estatuto da Cidade $^{14}$, que tem no Plano Diretor elemento fundamental, define os instrumentos que o poder público pode utilizar para garantir o cumprimento da função social da propriedade, a regularização fundiária e a gestão democrática e participativa da cidade. Foram apontadas diretrizes gerais, e dessas, as que interessam para o trabalho, são:

I - garantia do direito a cidades sustentáveis, entendido como o direito à terra urbana, à moradia, ao saneamento ambiental, à infraestrutura urbana, ao transporte e aos serviços públicos, ao trabalho e ao lazer, para as presentes e futuras gerações;

II - gestão democrática por meio da participação da população e de associações representativas dos vários segmentos da comunidade na formulação, execução e acompanhamento de planos, programas e projetos de desenvolvimento urbano;

III - cooperação entre os governos, a iniciativa privada e os demais setores da sociedade no processo de urbanização, em atendimento ao interesse social; IV - planejamento do desenvolvimento das cidades, da distribuição espacial da população e das atividades econômicas do Município e do território sob sua área de influência, de modo a evitar e corrigir as distorções do crescimento urbano e seus efeitos negativos sobre o meio ambiente;

\footnotetext{
11 Fernando Collor de Mello foi presidente do Brasil de 1990 a 1992.

12 Itamar Augusto Cautiero Franco foi presidente do Brasil, tendo governado entre 1992 e 1995 após seu antecessor, Fernando Collor, ter sido afastado da presidência por um processo de impeachment. ${ }_{13}$ Fernando Henrique Cardoso foi presidente do Brasil entre 1995 e 2003.

14 Disponível em: http://www.planalto.gov.br/ccivil_03/leis/leis_2001//10257.htm Acesso em: 26 jun 2019.
} 
$\mathrm{V}$ - oferta de equipamentos urbanos e comunitários, transporte e serviços públicos adequados aos interesses e necessidades da população e às características locais.

O Estatuto da cidade surgiu para dar o suporte jurídico mais consistente e estratégico às políticas públicas de habitação, de forma que o planejamento ocorra de forma integrada e consciente para operacionalizar a sociedade, garantindo a função social da propriedade, o planejamento participativo nas políticas urbanas e o acesso livre. Foi, em anos, a primeira medida comprometida com a regularização fundiária que se pratica no país, "definindo uma concepção de intervenção no território que se afasta da ficção tecnocrática" (ROLNIK, 2001). Todavia, a aprovação do estatuto não é garantia de qualidade de vida para os que são historicamente desfavorecidos, mas simboliza um aparato legal para tanto.

Já no Governo Lula ${ }^{15}$, a principal política para habitação foi o Programa Minha Casa, Minha Vida (MCMV), lançado para construir moradia para a população de baixa renda. Além da proposta social, destacava-se por ser uma ferramenta do governo para aquecer o mercado interno, frente à crise econômica internacional, estimulando a criação de empregos e investimento no setor de construção civil, e ganhou relevância e representatividade como um todo no país.

Entretanto, a estrutura do projeto deixa a desejar, pois mais uma vez a iniciativa privada é protagonista, assim como os outros grandes programas FCP e o BNH. Esse protagonismo entregue aos empresários favorece a segregação espacial, que está atrelada à política de mercado de terras (especulação imobiliária) com as construtoras, buscando os terrenos mais baratos, que em regra estão em zonas mais afastadas, zonas periféricas. O fato é que, "os pobres não cabem nas cidades, que os conjuntos habitacionais têm sido construídos em terras baratas a longas distâncias" (MERICATO, 2009). Logo, o mercado imobiliário no Brasil é para poucos, dessa forma o MCMV repete erros do passado com a construção de grandes conjuntos em áreas isoladas e com infraestrutura deficiente.

A formação do espaço urbano brasileiro está subordinada aos imperativos da acumulação do capital, de tal forma que a sociedade se organiza de acordo com a hierarquização social. Assim, "a cidade capitalista é desigual e o processo de urbanização tem produzido e aprofundado as desigualdades e injustiças da cidade" (HARVEY apud CANETTIERI, et al., 2012 p.3), pois é realizado para atender os interesses da acumulação de capital. Portanto, a dinâmica organizacional do urbano é concernente aos fatores políticos, econômicos e sociais,

${ }^{15}$ Luiz Inácio Lula da Silva foi presidente do Brasil de 2003 a 2011

DIGNIDADE RE-VISTA | ISSN2525-698X| 2018 | V. IV | N. 8 | Políticas Públicas e Direitos Humanos. Pastoral Universitária Anchieta PUC-RIO. 
que se refletem na infraestrutura e no uso desigual dos territórios. A ocupação do espaço urbano brasileiro pelos mais pobres se caracteriza socialmente como injusta e excludente. No que tange aos aspectos socioespaciais, na ocupação de áreas impróprias à moradia, as denominadas favelas, assentamentos precários, aglomerados. Localizadas majoritariamente nas periferias, distantes dos centros urbanos ou mesmo localizadas em zonas centrais, próximas a bairros valorizados pelo mercado imobiliário, mas em áreas de topologia imprópria à construção, geralmente sujeitas a situações de risco geológico.

Henri Lefebvre chama a atenção para o fato de se tratar do capitalismo dando solução aos graves problemas que ele mesmo gerou. O urbanismo oculta, encobre e dissimula seus traços fundamentais, "sob uma aparência positiva, humanista, tecnológica, a estratégia capitalista: o domínio do espaço, a luta contra a queda tendencial do lucro médio e etc” (LEBEBVRE, 1999, p.143). A mercantilização do solo impede o acesso democrático à população que nele vive. Nesse sentido, o valor de uso é comandado pela questão econômica, sem considerar o aspecto social. O Estado revela-se necessário, porém insuficiente na promoção do planejamento, de modo a garantir o direito social à moradia e o pleno desenvolvimento das funções. Como salienta Maricato:

\begin{abstract}
Nunca é demais repetir que não é por falta de planos e nem de legislação urbanística que as cidades brasileiras crescem de modo predatório. Um abundante aparato regulatório normatiza a produção do espaço urbano no Brasil [...] a condição de ilegalidade em que vive grande parte da população urbana brasileira em relação à moradia e a ocupação da terra demonstrando que a exclusão social passa pela lógica da aplicação discriminatória da lei. (2000, p.147)
\end{abstract}

\title{
Conclusão
}

A realidade complexa e ambígua entre o legal e o ilegal das moradias é concernente à ineficiência da legislação, que contribui ao exercício arbitrário do poder, favorecendo pequenos interesses corporativos. A ocupação ilegal e acelerada de terra urbana não é apenas permitida, como faz parte do modelo de desenvolvimento urbano do Brasil, explícito na manutenção da desigualdade socioespacial na qual há pouca implementação de equipamentos urbanos básicos (saneamento; pavimentação; espaço de lazer; transporte; oportunidade de emprego), e também na desigualdade socioeconômica que afeta diretamente a qualidade de vida (baixos salários, pouca escolaridade; violência; miséria), latente nos lugares de maior vulnerabilidade social, colocando em risco a dignidade humana e o desenvolvimento social. 
O Estado demonstra ser o principal responsável pelo alto déficit habitacional do país e, para equacionar essa problemática, é necessária uma reforma estrutural do aparelho do Estado, pois, enquanto a ilegalidade for funcional, as relações políticas arcaicas do mercado imobiliário serão sobrepostas a toda e qualquer necessidade urbana e humana.

A partir das características expostas pelos sucessivos governos, é possível notar um padrão de descontinuidade nas estratégias de políticas habitacionais caracterizadas como políticas públicas de curto prazo, que são válidas enquanto durar o mandato vigente ou enquanto for viável economicamente, negligenciando a efetividade do programa e a real demanda da população. Esse fato é funcional para o governo que tem a possibilidade de começar do zero e pode ser lembrado positivamente caso tenha êxito; por outro lado, é prejudicial aos cidadãos que necessitam efetivamente de moradia e são os maiores financiadores de políticas públicas que não evoluem ao longo do tempo, já que não há real interesse em desenvolvimento pelo poder público.

As tentativas de resolver o problema da moradia são absolutamente ineficazes, o que torna estrutural e institucionalizado o problema de habitação no Brasil, pois não há - por parte do Estado - o real comprometimento em garantir a cidadania e uma sociedade igualitária para o povo pobre. Dessa maneira, é necessário extirpar políticas públicas compensatórias que apenas fomentam a divisão econômica, espacial e social nas cidades. 


\section{Referências bibliográficas}

AZEVEDO, Sergio. Vinte e dois anos de política de habitação popular (1964-86): Criação, trajetória e extinção do BNH. Disponível em: http://bibliotecadigital.fgv.br. Acesso em: 4 nov 2019.

BARON, Cristina. M. B. A produção da habitação e os conjuntos habitacionais dos Institutos dos Aposentados e Pensão - IAPs. Revista Tópos, v.5, n.2, 2011. Disponível em: http://revista.fct.unesp.br. Acesso em: 23 jul 2019.

CANETTIERI, Thiago; PEREIRA, Thiago; LIBERATO, Rita C. Uma contribuição para o entendimento da segregação urbana: exploração, dominação e valorização. Revista Espinhaço, UFVJM, p.3-13, mar. 2017.

HARVEY, David. Cidades Rebeldes: do direito à cidade à revolução urbana. Trad. Jeferson Camargo. São Paulo: Martins Fontes - Selo Martins, 2014.

LEFEBVRE, Henri. A Revolução Urbana. Trad. Sergio Martins. Belo Horizonte: Editora, UFMG, 1999.

MARICATO, Ermínia. A Cidade do Pensamento Único: desmanchando Consensos. As idéias fora de lugar, Petrópolis: Vozes, 2000.

2003.

Metrópole, legislação e desigualdade. Estudos Avançados, v.17 n.48, p.151-66, 1 ago

O "Minha Casa" é um avanço, mas segregação urbana fica intocada. Carta Maior, mai de 2009. Disponível em: http://cartamaior.com.br. Acesso em: 5 out 2019.

MELO, Marcos A. B. C. Política de habitação e populismo: o caso da fundação da casa popular. Revista de Urbanismo e Arquitetura, v.3, n.1, 1990.

MENDES, Juliana; CASSAB, Clarice. Programas habitacionais e a Produção do Espaço: Processos de Des-re-territorialização de Jovens Pobres em Duas Cidades Médias. Revista de Geografia, v.3, n.1, 2013.

SANTOS, Milton. A urbanização Brasileira. 5.ed. São Paulo: Editora da Universidade de São Paulo, 2008.

SOUSA, José N. A exclusão pela urbanização favela: Governo e conflito na cidade do Rio de Janeiro. GEOgraphia, v.5, n.10, 2003.

SOUZA FILHO, Carlos F. M. Terra mercadoria, terra vazia: povos, natureza e patrimônio cultural. Revista InSURgência, Brasília, ano 1, v.1, n.1, jan/jun 2015.

PERISSINOTTO, Renato M. Hegemonia Cafeeira e "regime político oligárquico". Revista de Sociologia e Política, n.6/7, 1996. 
MACIEL, Gabriela. Políticas habitacionais brasileiras: a elucidação de um padrão de segregação socioeconômica e socioespacial.

ROLNIK, Raquel. Estatuto da Cidade - instrumento para as cidades que sonham crescer com justiça e beleza. Instituto Polis. Publicado em: 6 nov 2001. Disponível em: https://polis.org.br/uploads/814/814.pdf. Acesso em: 10 jan 2019. 